\title{
Modelling of Technical Efficiency of Indian Scientific Laboratories using Data Envelopment Analysis (DEA)
}

\author{
Abhishek Kumar ${ }^{1}$, Alpana Srivastava ${ }^{1}$, Rajesh Tiwari ${ }^{1}$, and R P Jeevan Kumar ${ }^{2}$ \\ ${ }^{1}$ Amity University - Lucknow Campus \\ ${ }^{2}$ PepsiCo India Holding Limited
}

December 8, 2021

\begin{abstract}
Performance Measurement $(\mathrm{PM})$ is a thoughtful demand of every sector for a sustainable growth. There are intangible factors known as economic growth drivers, where Research and Development (R\&D), is a vital indicator. As per Global Innovation Index-2020, India ranks 48th among the 131 economies for its education, software exports, R\&D and market value. Every year, a massive amount is invested in research labs but the output generated is much lower as compared to world average. Measurement of Scientific Productivity (SP) is a genesis of this though. Earlier, Publications and Patents were considered as means to identify growth but there exists a need holistic measurement of innovative potential. In this study, Technical Efficiency (TEs) of Indian Scientific Laboratories (CSIR) was measured using Data Envelopment Analysis (DEA) with few more parameters - Scientific Performance Indicators (SPIs). This study concluded with demarcation of efficient and lesser efficient laboratories during a specific period. This study would contribute towards an introspection by policy makers and government to re-evaluate the organizational outputs as per their mandates. Such studies are envisaged to assess the strength and weakness and furthermore, plan to contribute efficiently to increase in productivity of organization and national economy as well.
\end{abstract}

\section{Hosted file}

MS_-_Blind.doc available at https://authorea.com/users/450246/articles/548601-modelling-oftechnical-efficiency-of-indian-scientific-laboratories-using-data-envelopment-analysisdea 